\title{
Soluble amyloid precursor protein: a novel proliferation factor of adult progenitor cells of ectodermal and mesodermal origin
}

\author{
Michael P Demars ${ }^{1}$, Amelia Bartholomew², Zuzana Strakova ${ }^{3}$ and Orly Lazarov ${ }^{1 *}$
}

\begin{abstract}
Introduction: Soluble amyloid precursor protein $\alpha$ (SAPP $\alpha$ ) is a proteolyte of APP cleavage by $\alpha$-secretase. The significance of the cleavage and the physiological role of SAPPa are unknown. A crystal structure of a region of the amino terminal of SAPP $\alpha$ reveals a domain that is similar to cysteine-rich growth factors. While a previous study implicates SAPPa in the regulation of neural progenitor cell proliferation in the subventricular zone of adult mice, the ubiquitous expression of APP suggests that its role as a growth factor might be broader.

Methods: SAPP $\alpha$ and $\alpha$-secretase activities were determined in neural progenitor cells (NPCs), mesenchymal stem cells (MSC) and human decidua parietalis placenta stem cells (hdPSC). Inhibition of $\alpha$-secretase was achieved by treatment with the matrixmetalloproteinase inhibitor GM6001, and proliferation was determined using clonogenic and immunocytochemical analysis of cell-lineage markers. Recovery of proliferation was achieved by supplementing GM6001-treated cells with recombinant soluble APP $\alpha$. Expression of APP and its cellular localization in the subventricular zone was determined by Western blot and immunohistochemical analyses of APP wild type and knockout tissue. Alterations in PERK and PAKT expression as a function of soluble APPa production and activity in NPCs were determined by Western blot analysis.

Results: Here we show that SAPP $\alpha$ is a proliferation factor of adult NPCS, MSCs and hdpPSC. Inhibition of $\alpha$ secretase activity reduces proliferation of these stem cell populations in a dose-dependent manner. Stem cell proliferation can be recovered by the addition of SAPP $\alpha$ in a dose-dependent manner, but not of media depleted of SAPP $\alpha$. Importantly, SAPP $\alpha$ operates independently of the prominent proliferation factors epidermal growth factor (EGF) and basic fibroblast growth factor (bFGF), but in association with ERK signaling and MAP-kinase signaling pathways. Levels of SAPP $\alpha$ and putative $\alpha$-secretase, ADAM10, are particularly high in the subventricular zone of adult mice, suggesting a role for SAPP $\alpha$ in regulation of NPCs in this microenvironment.

Conclusions: These results determine a physiological function for SAPP $\alpha$ and identify a new proliferation factor of progenitor cells of ectodermal and mesodermal origin. Further, our studies elucidate a potential pathway for sAPP $\alpha$ signaling through MAP kinase activation.
\end{abstract}

\section{Introduction}

Amyloid precursor proteins (APPs) comprise a family of evolutionarily conserved single-pass type I transmembrane glycoproteins of an unknown physiological function. In mammals, that family includes APP and amyloid precursor-like protein 1 and 2 (APLP1 and APLP2) (reviewed in [1]). Mutations in APP cause

\footnotetext{
* Correspondence: olazarov@uic.edu

'Department of Anatomy and Cell Biology, The University of Illinois at

Chicago, 808 S Wood St. Rm. 572 Chicago, IL 60612, USA

Full list of author information is available at the end of the article
}

familial Alzheimer's disease (reviewed in [1]). APP undergoes extensive enzymatic processing, producing both intracellular and extracellular metabolites (reviewed in [2]). In its non-amyloidogenic pathway, APP is cleaved mostly on the plasma membrane by an enzymatic activity termed the $\alpha$-secretase $[3,4]$. $\alpha$-Secretase cleaves APP between Lys16 and Leu17 of the A $\beta$ region, resulting in the release of a soluble fragment (sAPP $\alpha)$ to the extracellular lumen and the retention of a membrane-tethered carboxyl-terminus fragment that undergoes further proteolysis (reviewed in [5]). The identity

\section{Biomed Central}


of $\alpha$-secretase is not fully elucidated. Several enzymesincluding members of the ADAM (a disintegrin and metalloproteinase) family ADAM10 [6], ADAM17 (TACE) [6-9], and ADAM9 as well as aspartyl protease beta-site APP-cleaving enzyme 2 (BACE2) [10]-are known to have $\alpha$-secretase activity. Like APP, APLP2 is a substrate of ADAM10 and 17 [11]. Both ADAM10 and 17 are implicated in development-regulated notch signaling by ectodomain shedding of Notch ligands Delta and Jagged [12]. ADAM10 was recently suggested to be the main $\alpha$-secretase in the brain [13].

SAPP $\alpha$ has been shown to exhibit neurotrophic and proliferative properties in fibroblasts [14], thyroid epithelial cells [15], and embryonic stem cells [16]. A crystal structure of a region of the amino terminal of sAPP $\alpha$ also reveals a domain that is similar to cysteinerich growth factors, suggesting that sAPP $\alpha$ may act as a potential ligand for growth factor receptors [17]. Indeed, epidermal growth factor (EGF)-responsive neural progenitor cells (NPCs) in the subventricular zone (SVZ) have been shown to have binding sites for SAPP [18]. Deficiency of the sortilin-related receptor with type-A repeats (SORLA) results in enhancement of SAPP production, extracellular signal-regulated kinase (ERK) stimulation, and increased proliferation and survival of NPCs in both the SVZ and subgranular layer of the dentate gyrus (SGL) [19]. Taken together, these results suggest that APP may act as a growth factor in promoting cellular proliferation. However, there has been no follow-up to these studies. It is not clear what populations of NPCs sAPP $\alpha$ acts upon, whether it is a stand-alone factor or a co-factor, or whether it regulates non-neural adult stem cell populations.

Here, we show that the production of sAPP $\alpha$ by $\alpha$ secretase processing of APP is an important event for the promotion of proliferation in a wide range of stem cell populations. We show, specifically, that sAPP $\alpha$ regulates the proliferation of NPCs, mesenchymal stem cells (MSCs), and Human decidua parietalis placenta stem cells (hdpPSCs). Importantly, sAPP $\alpha$ is a standalone proliferation factor, exerting its proliferative effect in an EGF- and basic fibroblast growth factor (bFGF)independent manner. In the brain, levels of sAPP $\alpha$ are particularly high in the SVZ. In addition, we show that, in NPCs, sAPP $\alpha$ function is associated with the ERK signaling pathway. These results suggest that sAP $\alpha$ is an essential proliferation factor for neural and nonneural adult stem cells. These observations further provide a functional significance for the abundance of APP.

\section{Materials and methods}

\section{Primary neurosphere culture}

Two-month-old C57/Bl6 wild-type mice were euthanized and their brains were removed and placed into sterile Dulbecco's modified Eagle's medium/F12 (DMEM/F12). A coronal slice (approximately $1 \mathrm{~mm}$ ) was dissected starting 1 to $2 \mathrm{~mm}$ posterior to the olfactory bulb. The region occupying the lateral wall and anterior horn of the lateral ventricles was removed with the aid of a dissecting microscope and diced with a sterile scalpel. Neurosphere culture was prepared as previously described [20]. Briefly, tissue pieces were collected in a mixture of Papain and DNase in Earl's balanced salt solution and incubated at $37^{\circ} \mathrm{C}$ for $40 \mathrm{~min}$ utes. Then, tissue pieces were pelleted by centrifugation and dissociated to a single-cell suspension, and cells were plated in complete medium-water, DMEM/F12 (Gibco, now part of Invitrogen Corporation, Carlsbad, CA, USA), glucose (Sigma-Aldrich, St. Louis, MO, USA), $\mathrm{NaHCO}_{3}$ (Sigma-Aldrich), HEPES (SigmaAldrich), L-glutamine (Invitrogen Corporation), penicillin/streptomycin (Invitrogen Corporation), putrescine $(9.6 \mu \mathrm{g} / \mathrm{mL}$; Sigma-Aldrich), apotransferrin $(0.1 \mathrm{mg} / \mathrm{mL}$; Sigma-Aldrich), insulin $(0.025 \mathrm{mg} / \mathrm{mL}$; Roche, Indianapolis, IN, USA), selenium (5.2 ng/mL; Sigma-Aldrich), progesterone $(6.3 \mathrm{ng} / \mathrm{mL}$; Sigma-Aldrich), bovine serum albumin (BSA) (2 mg/mL; Sigma-Aldrich), heparin (4 $\mu \mathrm{g} / \mathrm{mL}$; Sigma-Aldrich), EGF (20 ng/mL; PeproTech, Rocky Hill, NJ, USA), and bFGF (10 ng/mL; PeproTech)-and passaged after 10 days.

\section{Isolation of mesenchymal stem cells}

After euthanasia, the bone marrow contents of the femurs and tibia of donor Balb/C mice were flushed through a $40-\mu \mathrm{m}$ filter (Becton, Dickinson and Company, Franklin Lakes, NJ, USA) into a 50-mL tube (Corning, Corning, NY, USA) containing MSC media: 40\% alpha-modified Eagle's medium (Invitrogen Corporation, Rockville, MD, USA), 40\% F-12 nutrient mixture (Invitrogen Corporation), 10\% fetal bovine serum (Valley Biomedical, Winchester, VA, USA), and 1\% antibiotic-antimycotic solution (Invitrogen Corporation). Bone marrow cells were plated at a density of $20 \times 10^{6}$ per $9.6 \mathrm{~cm}^{2}$ in $\mathrm{MSC}$ media at $37^{\circ} \mathrm{C}$ in $5 \% \mathrm{CO}_{2}$ as previously described [21]. The non-adherent population was removed after 72 hours, and the adherent cells were washed with fresh media and cultured for 7 days. The resulting adherent cells were harvested by incubating with $0.25 \%$ trypsin (Invitrogen Corporation) followed by gentle scraping. By means of negative selection via immunomagnetic column (Miltenyi Biotec, Auburn, CA, USA), cells negative for CD11b (eBioscience, San Diego, CA, USA) and CD45 (eBioscience) were placed back into culture. A homogenous cell phenotype was confirmed on the basis of the expression of CD29, CD44, and Sca1 and the absence of hematopoietic (CD45, CD14, and CD11b) markers. Prior to use, cells had been passaged from one to four times. 


\section{Human decidua parietalis placenta stem cells}

All studies were approved by the Institutional Review Board of the University of Illinois. hdpPSCs were isolated from the decidua parietalis dissected from placental membranes after normal vaginal delivery at term, as previously described in detail [22]. Human placenta tissue was obtained from the Human Female Reproductive Tissue bank in the Center for Women's Health and Reproduction at the University of Illinois at Chicago. Cells were cultured in RPMI-1640 medium supplemented with $10 \%$ heat-inactivated and charcoal-stripped fetal bovine serum, $0.1 \mathrm{mM}$ sodium pyruvate, and $1 \%$ penicillin/streptomycin. At confluence, cells were trypsinized, propagated, and used for experiments in passage numbers three to five.

\section{Recombinant sAPP}

sAPP (Sigma-Aldrich) was used at $10 \mathrm{nM}$ concentrations unless otherwise indicated (dissolved in phosphate-buffered saline, or PBS).

\section{Conditioned media}

Neurosphere media was conditioned by plating $3 \times 10^{5}$ NPCs in each well of a 12-well plate in $500 \mu \mathrm{L}$ of complete media. After 1 hour, media was removed and spun at $1,000 \mathrm{~g}$ for 10 minutes to remove any cells or debris. For depletion of SAPP, conditioned media was precleared with protein A-agarose beads (Pierce, Rockford, IL, USA) and then incubated overnight at $4{ }^{\circ} \mathrm{C}$ with $22 \mathrm{C} 11$ antibodies against the $\mathrm{N}$-terminus of APP or IgG antibodies (Millipore Corporation, Billerica, MA, USA) as a control. Protein A-agarose beads were added for 30 minutes, the mixture was spun at 4,000 revolutions per minute (rpm) for 3 minutes, and the supernatant was used as depleted media. Regular conditioned media was subjected to the same process without antibody incubation as a control. All media was filtered through a $0.22-$ $\mathrm{mm}$ filter prior to addition.

\section{Detection of SAPP}

For the detection of soluble APP from brain lysates, protein was extracted in immunoprecipitation buffer containing $150 \mathrm{mM} \mathrm{NaCl}, 50 \mathrm{mM}$ Tris-Cl, $5 \mathrm{mM}$ ethylenediaminetetraacetic acid (EDTA), 1\% Triton-X 100, $0.5 \%$ sodium deoxycholate, protease inhibitor cocktail, and $250 \mu \mathrm{M}$ phenylmethylsulfonyl fluoride (PMSF). To remove full-length APP, protein samples were immunodepleted by using 369 antibodies against the C-terminus of APP (a gift from Sangram S Sisodia, The University of Chicago). Briefly, samples were precleared with $50 \mu \mathrm{L}$ of immobilized protein A-agarose beads (Pierce) at $4^{\circ} \mathrm{C}$ for 30 minutes. Samples were centrifuged at 4,000 rpm for 3 minutes, and the pellet was discarded. To the supernatant, $5 \mu \mathrm{L}$ of 369 antibody was added and incubated overnight at $4{ }^{\circ} \mathrm{C}$. The next morning, $50 \mu \mathrm{L}$ of immobilized protein A was again added for 30 minutes at $4{ }^{\circ} \mathrm{C}$ and spun at $4,000 \mathrm{rpm}$ for 3 minutes. The pellet contains the full-length APP-369 antibody complex, and the supernatant was probed for sAPP by using $22 \mathrm{C} 11$ antibodies raised against the N-terminus of APP (Millipore Corporation).

\section{Neurosphere formation (clonogenic) assay}

Briefly, neurospheres were singly dissociated by mechanical dissociation and plated at 1,000 cells per well onto 96-well plates. For matrix-metalloproteinase (MMP) inhibitor experiments, cells were then treated with the indicated molar concentration of GM6001 or GM6001 negative control (Millipore Corporation) and the indicated molar concentrations of SAPP or conditioned media. If not otherwise indicated, $1 \mu \mathrm{M}$ GM6001 and negative control inactive inhibitor (NC) were used. Cells were treated every 72 hours for 10 days. After 10 days in culture, neurospheres were counted under an inverted light microscope, and the average neurosphere diameter was calculated from 25 randomly assigned squares of the grid by using a Zeiss AX10 microscope (Carl Zeiss Ltd., Hertfordshire, UK) and StereoInvestigator software (MBF Bioscience, Williston, VT, USA). After sphere size determination, cells were singly dissociated with a p200 pipette and counted with a hemocytometer. The remaining cells were placed onto Matrigel-coated chamber slides for 30 minutes and then fixed in $4 \%$ paraformaldehyde for 30 minutes for immunocytochemistry. Briefly, cells were washed four times in Tris-buffered saline (TBS) and then placed into blocking solution (5\% normal donkey serum, $0.25 \%$ Triton-X 100 in TBS) for 30 minutes at room temperature. Next, cells were incubated in primary antibodies-mouse anti-nestin (1:100; Millipore Corporation) and goat anti-Sox2 (1:200; Santa Cruz Biotechnology, Inc., Santa Cruz, CA, USA)in TBS containing $0.25 \%$ Triton-X 100 for 1 hour at room temperature. After primary antibodies, cells were again incubated in blocking solution for 30 minutes at room temperature before secondary antibody incubation-anti-goat cy5 (1:250; Jackson ImmunoResearch Laboratories, Inc., West Grove, PA, USA) and antimouse cy3 (1:500; Jackson ImmunoResearch Laboratories, Inc.)-in TBS with $0.25 \%$ Triton-X 100 for 30 minutes at room temperature in the dark. Cells were then washed four times in TBS and incubated for 5 minutes with DAPI (4'-6-diamidino-2-phenylindole) (1:50,000; Invitrogen Corporation) at room temperature in the dark. Cells were then washed three times and mounted with polyvinyl alcohol-DABCO mounting solution. Cell counts were made by means of StereoInvestigator software version 8 (MBF Bioscience). 
Mesenchymal and placental cell proliferation experiments MSC or hdPSC were trypsinized for 5 to 10 minutes with $0.05 \%$ trypsin, collected after trypsin inactivation, and spun at $500 \mathrm{~g}$ for 5 minutes. Pellets were then dissociated and plated at 1,000 cells per well in 96-well plates. Cells were then treated with the indicated molar concentration of GM6001 or GM6001 negative control (Millipore Corporation) and the indicated molar concentrations of sAPP. After 3 days in culture, cells were trypsinized for 5 to 10 minutes, spun, and counted with a hemocytometer.

\section{Brain tissue for biochemistry and immunohistochemistry}

Experiments using animals were performed according to guidelines of the National Institutes of Health and the University of Illinois at Chicago Institutional Animal Care and Use Committee. The APP knockout $[A P P(-/-)]$ model has been described previously [23,24]. Briefly, the authors generated the mice through homologous recombination in embryonic stem cells. Mice heterozygous for APP expression were cross-mated and $A P P(+/+)(A P P$ wild-type), $A P P(+/-)$, and $A P P(-/-)$ resulted from this breeding. Our colony is maintained via group housing (fewer than five mice per cage) in a barrier facility under a 14:10 light/dark cycle with free access to food and water. Animal care and procedures were conducted according to the National Institutes of Health Guide for the Care and Use of Laboratory Animals [25].

\section{Brain tissue processing}

For in vivo immunohistochemical staining, male APP $(+/+)$ mice from 3 to 5 months old were used. All mice were anesthetized with a mixture of ketamine and xylazine and transcardially perfused with $100 \mathrm{~mL}$ of ice-cold PBS. The brains were then removed and halved in the sagittal plane. The left half was immediately placed into $4 \%$ paraformaldehyde on ice. From the right half of the brain, the following regions were dissected for biochemical analysis and immediately placed into Eppendorf tubes on dry ice: SVZ, hippocampus, olfactory bulb, frontal cortex, and cerebellum.

\section{Immunohistochemistry}

Left hemibrains from PBS-perfused mice were post-fixed in $4 \%$ paraformaldehyde for 3 days and stored in $30 \%$ sucrose at $4^{\circ} \mathrm{C}$. Hemibrains were sectioned sagittally at $50 \mu \mathrm{m}$ by using a microtome and placed into cryopreservent (47.6\% PBS, 28.57\% ethylene glycol, and 25\% glycerin vol/vol). Sections were blocked by using a solution containing $0.25 \% \mathrm{vol} / \mathrm{vol}$ Triton-X 100 (SigmaAldrich) and 5\% vol/vol Normal Donkey Serum (Jackson ImmunoResearch Laboratories, Inc.) in TBS. The following antibodies were used: Dlx-2 (1:200; Millipore Corporation), nestin (1:100; Millipore Corporation), Sox2
(1:100; Santa Cruz Biotechnology, Inc.), ADAM10 (1:200; Millipore Corporation), and APP (22C11; Millipore Corporation and A8717; Sigma-Aldrich). Floating sections were incubated in primary antibodies for 72 hours at $4^{\circ} \mathrm{C}$ before continuing with blocking, biotin conjugation (Jackson ImmunoResearch Laboratories, Inc.), and secondary antibody incubation (cy2 Streptavidin, anti-mouse cy3, anti-goat cy5, and anti-rabbit cy5; Jackson ImmunoResearch Laboratories, Inc.).

\section{Western blotting}

Protein extraction from brain tissue was performed in lysis buffer containing $1 \mathrm{X}$ TNE, $50 \mathrm{mM}$ Tris, $150 \mathrm{mM}$ $\mathrm{NaCl}, 5 \mathrm{mM}$ EDTA, protease inhibitor cocktail (SigmaAldrich), and $100 \mathrm{mM}$ PMSF. Quantification of protein was performed by using the bicinchoninic acid (BCA) method (Pierce), and equal amounts of protein were subjected to direct immunoblotting. For the extraction of protein from neurosphere, mesenchymal, and Human decidua parietalis placenta stem cells cultures, a lysis buffer containing $150 \mathrm{mM} \mathrm{NaCl}, 50 \mathrm{mM}$ Tris-Cl, $5 \mathrm{mM}$ EDTA, 1\% Triton-X 100, 0.5\% sodium deoxycholate, protease inhibitor cocktail, and $250 \mu \mathrm{M}$ PMSF was used. For quantification, at least three cultures were used.

\section{Erk and Akt signaling}

To assay phosphorylation of Erk and Akt, neurospheres were singly dissociated and plated at $5 \times 10^{5}$ cells per well in a six-well plate in Earle's balanced salt solution (Sigma-Aldrich) and treated immediately with $1 \mu \mathrm{M}$ GM6001 or GM6001 negative control. After 1-hour incubation at $37^{\circ} \mathrm{C}$, one of the GM6001-treated groups was subsequently treated with $10 \mathrm{nM}$ recombinant sAPP $\alpha$ (Sigma-Aldrich) for 15 minutes before all groups were lysed in ROLB buffer: $10 \mathrm{mM}$ HEPES, pH 7.4, $0.5 \%$ Triton X-100, $80 \mathrm{mM} \beta$-glycerophosphate, $50 \mathrm{mM}$ sodium fluoride, $2 \mathrm{mM}$ sodium orthovanadate, $100 \mathrm{nM}$ staurosporine, $100 \mathrm{nM} \mathrm{K252a,} 50 \mathrm{nM}$ okadaic acid, 50 $\mathrm{nM}$ microcystin, mammalian protease inhibitor cocktail (Sigma-Aldrich), and phosphatase inhibitor cocktail II (Calbiochem, now part of EMD Biosciences, Inc., San Diego, CA, USA) in water. After lysis, protein quantification was performed by using the BCA method (Pierce), and equal amounts of protein were run on Tris-glycine gels and transferred to nitrocellulose membranes. For blocking and antibodies, we employed a solution of $0.05 \% \mathrm{vol} / \mathrm{vol}$ Tween, $10 \% \mathrm{wt} / \mathrm{vol} \mathrm{milk}$, and $0.1 \% \mathrm{wt} /$ vol BSA (Sigma-Aldrich) in TBS. The following antibodies were used: pErk (1:500; Santa Cruz Biotechnology, Inc.), Erk (1:1,000; Santa Cruz Biotechnology, Inc.), pAkt (1:1,000; Cell Signaling Technology, Inc., Danvers, MA, USA), and Akt (1:500; Cell Signaling Technology, Inc.). ( $\mathrm{N}=3$ for Erk and Akt Western blot quantification.) 


\section{Results \\ sAPP $\alpha$ rescues proliferation of neural progenitor cells after treatment with a matrix-metalloproteinase and ADAM inhibitor}

To examine the role of SAPP $\alpha$ in NPC proliferation and the significance of $\alpha$-secretase cleavage of APP in this process, NPCs isolated from the SVZ of adult mice were treated with GM6001, a potent broad-spectrum hydroxamic acid-based inhibitor of MMPs and ADAMs which has been shown to decrease levels of sAPP and sAPLP2 [11]. First, using Western blot analysis, we confirmed that levels of SAPP are reduced in the conditioned media of NPCs treated with GM6001 (Figure 1a, b). Next, we singly dissociated NPCs and treated them with either inactive inhibitor (NC) or GM6001 or with GM6001 and SAPP $\alpha$ in a neurosphere formation assay. We observed that treatment of neurosphere culture with GM6001 significantly reduced proliferation of NPCs in a dose-dependent manner (Figure 1c). Inhibition of NPC proliferation could be rescued by the addition of recombinant sAPP $\alpha$ (Figure 1c), suggesting that sAPP $\alpha$ is sufficient for the induction of NPC proliferation. To further characterize the effect of SAPP $\alpha$ on NPC proliferation, we repeated the clonogenic assay, treated singly dissociated NPCs with NC or GM6001 or with GM6001 and SAPP $\alpha$, and determined the number of neurospheres generated, their diameter, and the total number of NPCs (Figure 1d-f). We observed that, after treatment with GM6001, there were significant reductions in the diameter of neurospheres (Figure 1e) and the total number of NPCs observed in the cultures (Figure 1d) but not a significant reduction in the number of clones (Figure 1f), suggesting that treatment with GM6001 affects NPC proliferation without affecting clone formation capability. Likewise, treatment of neurosphere cultures with GM6001 and sAPP $\alpha$ significantly rescued impaired neurosphere diameter and total number of NPCs without affecting the number of neurospheres (Figure 1d-f). To determine whether recovery of NPC proliferation by sAPP $\alpha$ occurs in a dose-dependent manner, sAPP $\alpha$ was added to neurosphere culture at a concentration range of $100 \mathrm{pM}$ to $100 \mathrm{nM}$. sAPP $\alpha$ recovered NPC proliferation after GM6001 treatment in a concentration as low as $100 \mathrm{pM}$. Rescue of NPC proliferation increased as a function of SAPP $\alpha$ dose and was maximal at $10 \mathrm{nM}$ (Figure 1g). Taken together, these data suggest that $\alpha$ secretase cleavage of APP is an important event in NPC cell cycle control and that $\mathrm{sAPP} \alpha$ regulates NPC proliferation.

To determine the subpopulation of NPCs affected by GM6001 inhibition and recovered by sAPP $\alpha$, singly dissociated NPCs treated with GM6001 or GM6001 + SAPP $\alpha$ were allowed to form neurospheres in a clonogenic assay as before and then immunolabeled with antibodies raised against nestin, an intermediate filament protein expressed in stem and progenitor cells [26], and Sox2, a transcription factor expressed in neural stem cells (NSCs) and NPCs of the adult brain [27]. We show that the number of nestin ${ }^{+}$Sox $2^{+}$cells was significantly reduced after treatment with GM6001, and their number was fully recovered after addition of sAPP $\alpha$ (Figure $2 \mathrm{a}-\mathrm{c}, 2 \mathrm{e}, \mathrm{f})$, suggesting that $\mathrm{sAPP} \alpha$ affects the proliferation of both NSCs and NPCs. Thus, we proceeded to examine whether sAPP $\alpha$ affects self-renewal of NSCs (Figure 2d). For this purpose, secondary neurospheres were singly dissociated and cultured at one cell per well in 96-well plates, and the number of cells that generated tertiary neurospheres was quantified. We show that treatment of cells with GM6001 significantly reduced the number of generated neurospheres but that the addition of sAPP $\alpha$ significantly enhanced the number of neurspheres generated (Figure $2 \mathrm{~d}$ ), suggesting that sAPP $\alpha$ regulates both NSC self-renewal and NPC proliferation.

\section{SAPP $\alpha$ regulates neural progenitor cell proliferation in an} EGF- and bFGF-independent manner

To address whether SAPP $\alpha$ is a stand-alone proliferation factor or its proliferative effect depends on other growth factors, we first compared the ability of NPC-conditioned media containing $\mathrm{SAPP} \alpha$ to rescue NPC proliferation with that of conditioned media depleted of sAPP $\alpha$. We observed that conditioned media containing sAPP $\alpha$ successfully rescued NPC proliferation but that conditioned media depleted of $\mathrm{SAPP} \alpha$ failed to do so (Figure 3a). Next, we excluded proliferation factors (namely, EGF and bFGF) from the proliferation medium of NPCs and examined the rate of proliferation of cells by measuring clone formation and size (Figure $3 \mathrm{~b}$ ). As expected, neurosphere proliferation was reduced without EGF and bFGF. Interestingly, treatment of these neurospheres with GM6001 further reduced the extent of proliferation, suggesting that factors aside from EGF and bFGF regulate neurosphere proliferation (Figure $3 b$ ). Importantly, the addition of soluble APP $\alpha$ recovered GM6001-induced deficits in proliferation even without EGF and bFGF, suggesting that sAPP $\alpha$ operates independently of EGF and bFGF (Figure $3 \mathrm{~b}$ ). To determine whether sAPP $\alpha$ operates synergistically to these growth factors in regulation of neurosphere proliferation, we quantified the effect of $\mathrm{SAPP} \alpha$ in medium devoid of EGF/bFGF and supplemented with GM6001 as well as the effect of EGF/bFGF in a medium supplemented with GM6001 and compared the effect on neurosphere diameter with the effect of EGF/bFGF on neurosphere diameter in medium supplemented with the negative control for GM6001. We observed that the additive effect of sAPP $\alpha$ in medium devoid of EGF/bFGF and 


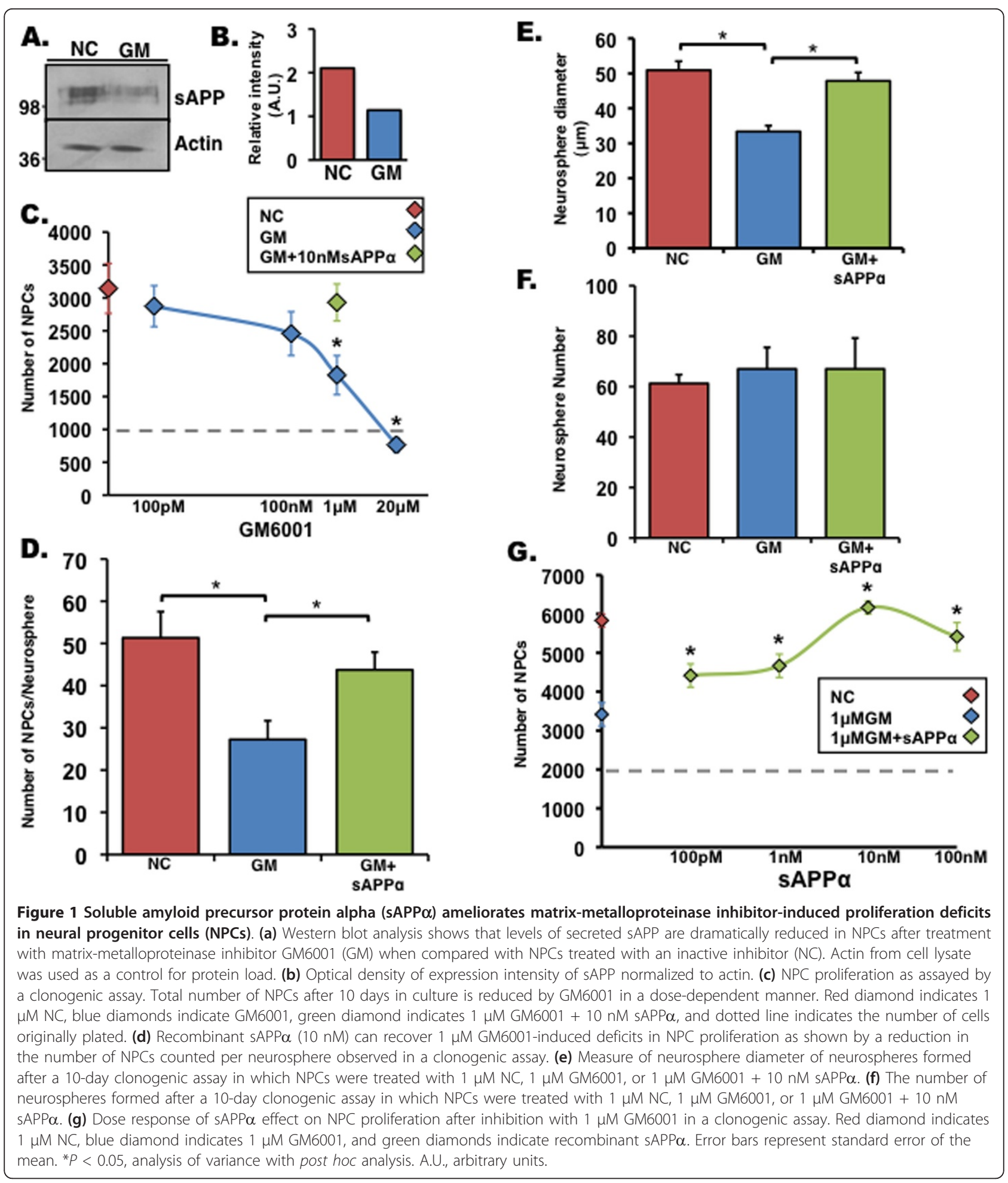

supplemented with GM6001 and the effect of EGF/ bFGF in a medium supplemented with GM is greater than the effect of EGF/bFGF in medium supplemented with the negative control for GM, suggesting a synergistic effect of sAPPa, EGF, and bFGF (Figure 3b).
sAPP $\alpha$ regulates the proliferation of adult stem cells of non-neural origin

As APP is ubiquitously expressed and was shown to act upon fibroblasts and thyroid epithelial cells $[14,15]$, we examined whether it regulates adult stem cells of non- 


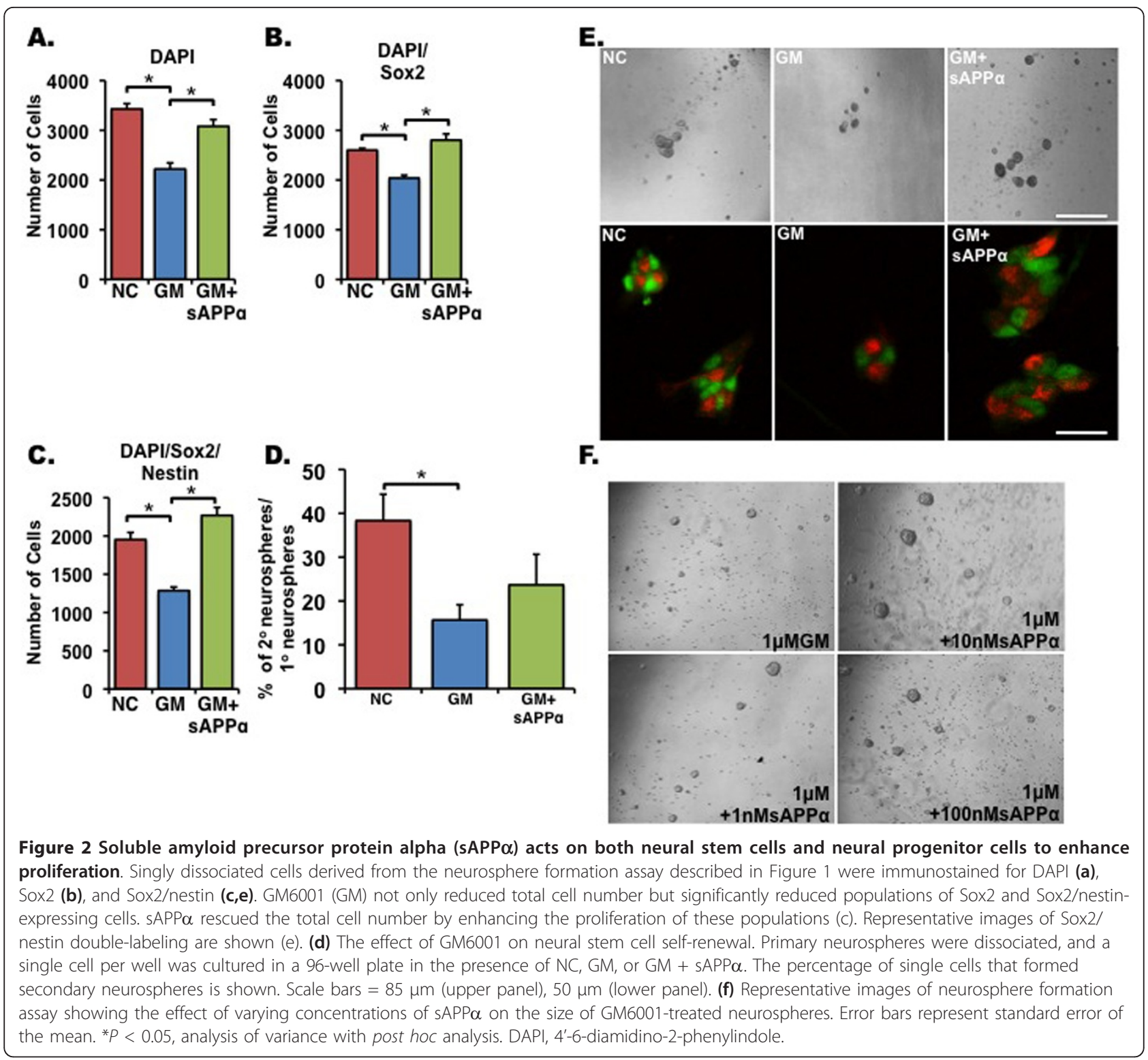

neural origin. Thus, we first tested whether reduced proliferation after inhibition of MMPs and ADAMs was cell-autonomous to NPCs or applied to other stem cell types. For this purpose, we examined the extent of proliferation of MSCs after GM6001 treatment. As in NPCs, GM6001 treatment reduced secreted levels of sAPP $\alpha$ (Figure 4a, b) and significantly reduced proliferation of MSCs (Figure 4c) in a dose-dependent manner, suggesting that MMP family members may play an important role in the proliferation of MSCs. The addition of recombinant $\mathrm{sAPP} \alpha$ significantly recovered MSC proliferation (Figure 4c, d). Like in the NPCs, 100 pM of SAPP $\alpha$ was sufficient to significantly rescue MSC proliferation and enhance their proliferation in a dosedependent manner (Figure 4e). Taken together, these results suggest that APP is expressed in MSCs and processed by $\alpha$-secretase activity to yield sAPP $\alpha$ that in turn regulates the proliferation of MSCs. Next, we investigated the effect of $\alpha$-secretase inhibition and sAPP $\alpha$ on the proliferative activity of hdpPSCs. The effect of GM6001 on hdpPSCs was similar to the one observed with NPCs and MSCs (Figure 5). Treatment with GM6001 significantly reduced levels of secreted sAPP $\alpha$ concomitantly with hdpPSC proliferation (Figure 5a-c), and this deficit was ameliorated by the addition of recombinant sAPP $\alpha$ in a dose-dependent manner (Figure $5 \mathrm{c}-\mathrm{e})$. Taken together, these results suggest that sAPP $\alpha$ is an essential proliferation factor of a variety of adult stem cells of different origins and provides a functional significance for the abundance of APP. 

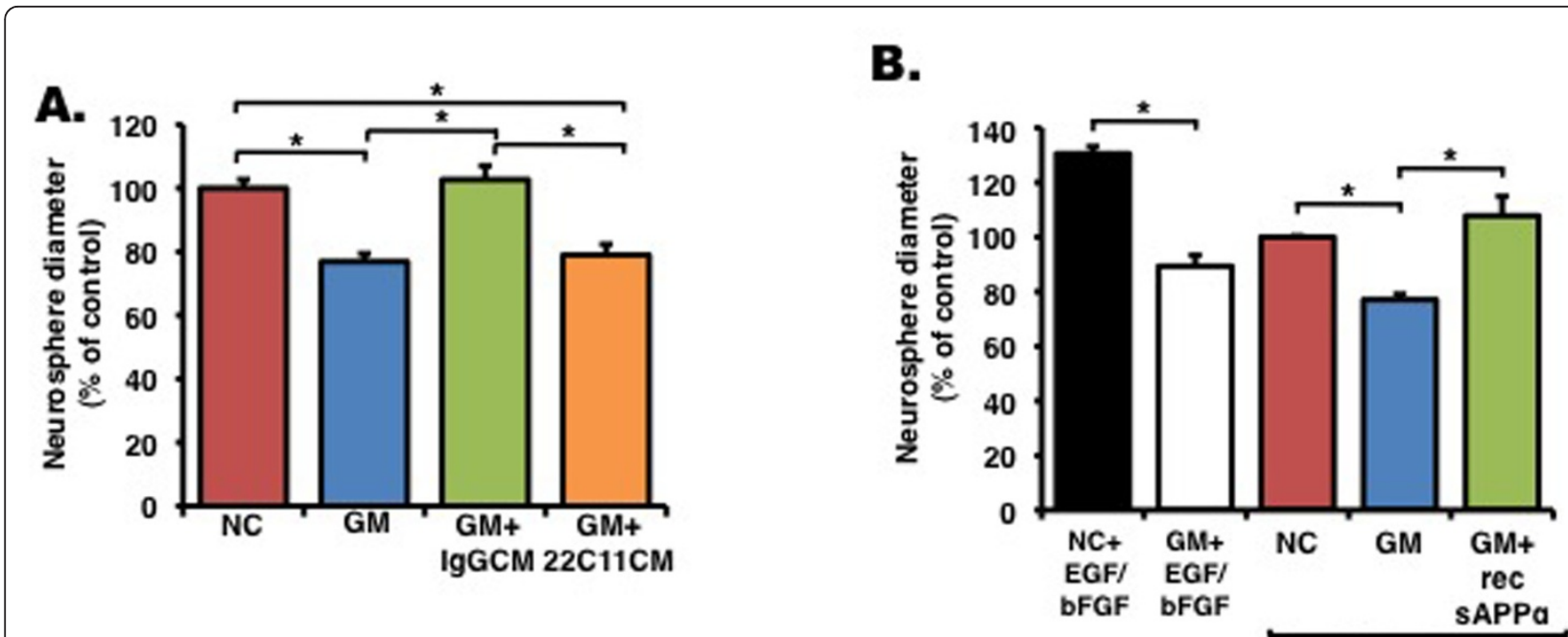

No EGF and bFGF

Figure 3 Soluble amyloid precursor protein alpha (SAPP $\alpha$ ) enhances proliferation in an EGF/bFGF-independent manner. (a) Neural progenitor cell (NPC)-conditioned media that has been immunodepleted of SAPP with 22C11 antibodies fails to recover GM6001-induced proliferation deficits of NPCs, as assayed by neurosphere diameter in a neurosphere formation assay. In contrast, NPC-conditioned media immunodepleted with control lgG antibodies successfully recovers NPC proliferation. (b) A neurosphere formation assay was performed without growth factors (EGF and bFGF), and NPCs were treated with an inactive inhibitor (NC), GM6001 (GM), or GM6001 + recombinant sAPP $\alpha$ (GM+rec SAPP $\alpha$ ). The proliferative effect of SAPP $\alpha$ on GM6001-treated neurosphere (GM) in medium devoid of EGF/bFGF and the proliferative effect of EGF/bFGF on GM6001-treated neurospheres are greater than the effect of EGF/bFGF on neurospheres treated with NC, suggesting a synergistic effect of SAPP $\alpha$ and EGF/bFGF. Error bars represent standard error of the mean. ${ }^{*} P<0.01$, analysis of variance with post hoc analysis. bFGF, basic fibroblast growth factor; EGF, epidermal growth factor.

High levels of sAPP are expressed in the subventricular zone of adult mice

To establish that sAPP $\alpha$ plays a role in proliferation of NPCs in vivo, we examined expression levels of fulllength APP and sAPP $\alpha$ in the SVZ, SGL, and a nonneurogenic region (cerebellum) of $A P P(-/-)$ and $A P P$ $(+/+)$ mice. For this purpose, we used antibodies recognizing the $\mathrm{NO}$-terminus of APP (22C11), thus recognizing both full-length APP and SAPP $\alpha$. We show that levels of $22 \mathrm{C} 11$ are comparable in the SGL and cerebellum with a trend of increased expression in the SVZ (Figure 6a). To examine whether this trend is a result of increased levels of sAPP $\alpha$ specifically, we immunodepleted full-length APP from the protein extract by using antibodies recognizing the carboxylterminus of APP, thus not capturing sAPP $\alpha$. We observed that levels of sAPP $\alpha$ were particularly high in the SVZ of both $A P P(+/+)$ and $A P P(+/-)$ (Figure 6b-d). These results support our notion that sAPP $\alpha$ plays a major role in the SVZ.

To determine whether the NSC and NPC populations that express APP resemble those observed in vitro in neurosphere culture, we double-stained brain sections of adult mice with antibodies raised against APP, Sox2, nestin, and Dlx-2, the last of which is a homeobox protein expressed in transit-amplifying $C$ cells of the adult SVZ [28]. APP expression colocalized with all three markers, suggesting that APP is expressed in NSCs and transit-amplifying NPCs in the adult SVZ (Figure 6e).

\section{ADAM10 is expressed in the subventricular zone and} hippocampus of adult mice

To examine whether high levels of SAPP $\alpha$ in the SVZ reflect levels of $\alpha$-secretase in this region, we examined expression of ADAM10, recently shown to be a critical $\alpha$ secretase during brain development [13]. We show that levels of ADAM10 are significantly higher in the SVZ compared with the SGL (Figure 7a, b). In support of a correlation between levels of SAPP $\alpha$ and ADAM10 is the observation that ADAM10 levels are lower in the SVZ of $A P P(-/-)$ compared with $A P P(+/+)$ (Figure 7a, c). To examine whether ADAM10 is expressed in the same neurogenic populations as APP, we immunostained brain sections with antibodies raised against ADAM10, nestin, Sox2, and BrdU 24 hours after a single dose. We observed that ADAM10 colocalizes with all three markers, suggesting that, like APP, ADAM10 is expressed in NSCs and transit-amplifying NPCs in the adult SVZ (Figure 7d, e).

\section{sAPP regulates extracellular signal-regulated kinase} activity

The mitogen-activated protein (MAP) kinase pathway plays an important role in the proliferation of NPCs derived from the adult SVZ [29]. Treatment with SAPP 


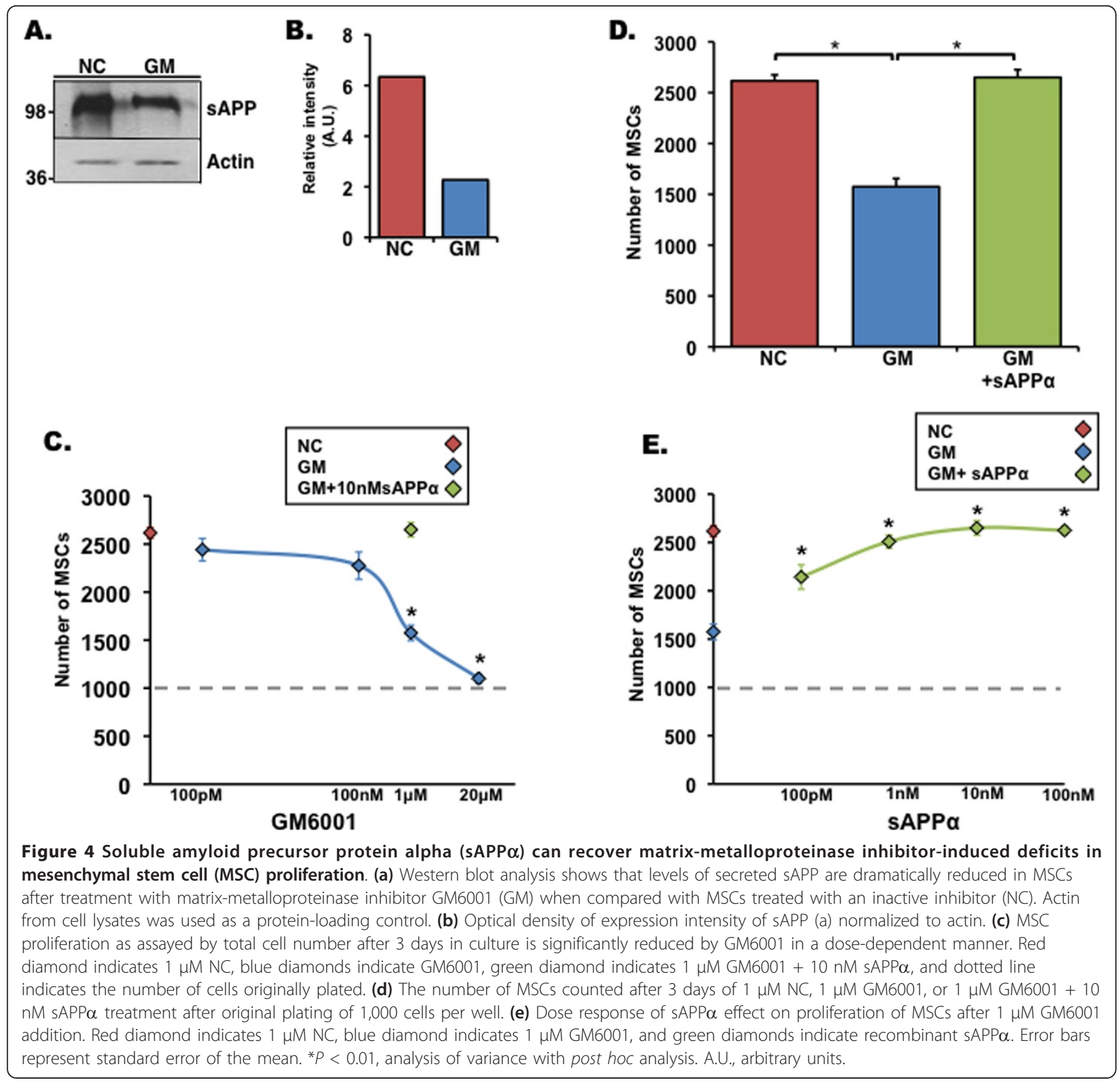

has been shown to stimulate ERK signaling in PC-12 cells [30], and SORLA-deficient mice showing enhanced APP cleavage to SAPP and A $\beta$ display increased neurogenesis and ERK signaling in hippocampal neurons [19]. Therefore, we tested whether inhibition of MMP activity, decreasing sAPP $\alpha$ production, would result in deficient ERK signaling. For this purpose, NPCs were treated with GM6001 as before and placed into Hank's balanced salt solution for 1 hour to remove any presence of exogenous growth factor signaling. Western blot analysis reveals that pERK is reduced approximately $25 \%$ in NPCs treated with GM6001 (Figure 8a, b). To examine whether this reduction can be recovered by addition of SAPP $\alpha$, we added recombinant sAPP $\alpha$ prior to lysing the cells. Recombinant sAPP $\alpha$ was able to reverse the deficits in ERK phosphorylation caused by GM6001 treatment (Figure 8a, b). To test whether this effect was specific to ERK, we examined another integral proliferation pathway known to respond to sAPP $\alpha$ [31], protein kinase B (Akt). Phosphorylation of Akt did not change significantly from negative control in any of the groups tested (Figure 8c, d), suggesting that sAPP $\alpha$ is associated specifically with ERK signaling.

\section{Discussion}

During the last two decades, there has been much interest in unraveling the physiological role of APP, its 


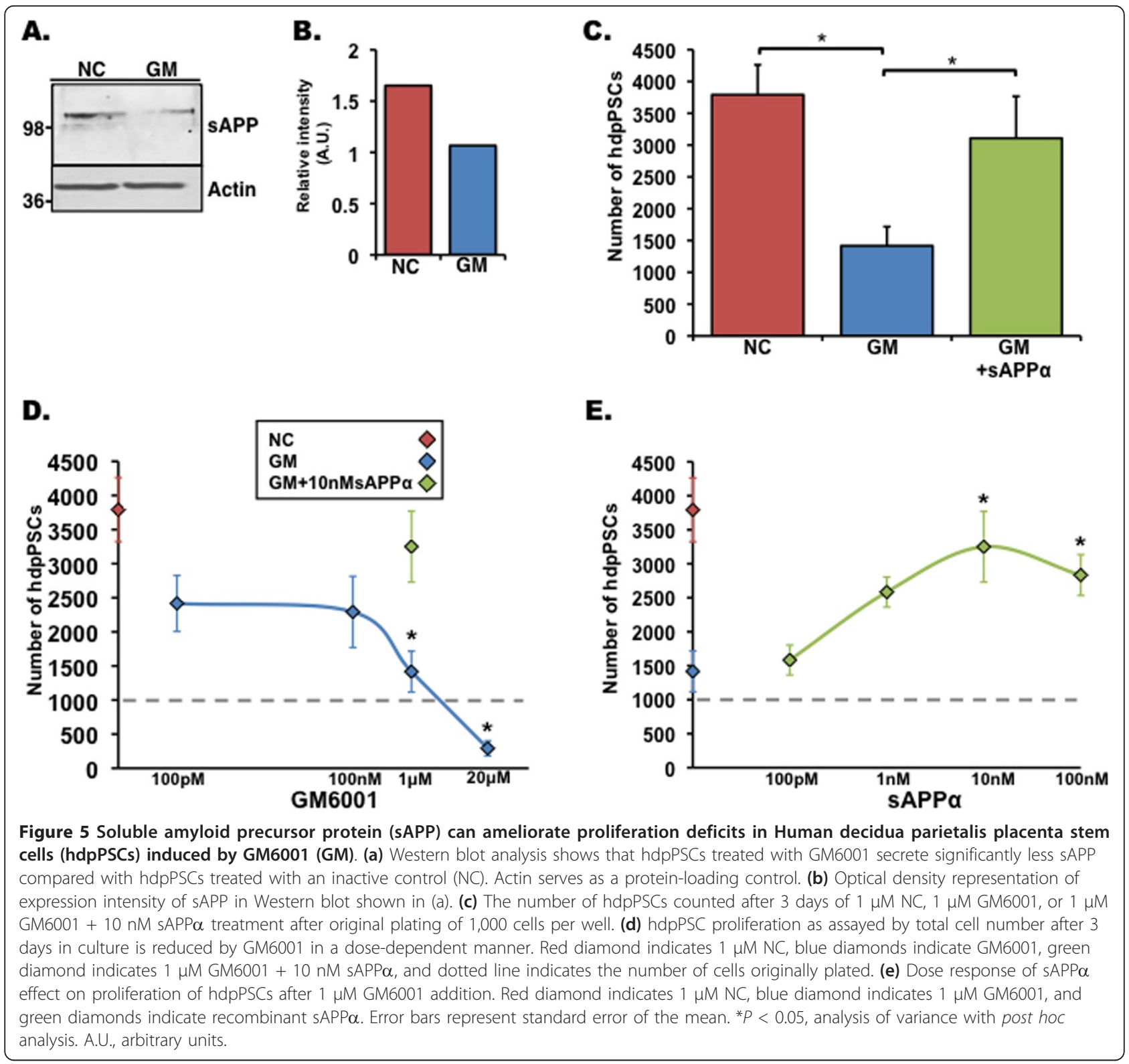

metabolites, and the physiological significance of its multiple metabolic pathways. Here, we show that sAPP $\alpha$, a product of APP cleavage by $\alpha$-secretase, is a proliferation factor of NPCs in the adult brain, MSCs, and hdpPSCs. This suggests an important role for sAPP $\alpha$ as a proliferation factor of different stem cell populations in the adult. The diversity of stem cells that respond to SAPP $\alpha$ as a proliferation factor leads us to suggest that SAPP $\alpha$ exerts its effect on a wide range of stem cell populations. NPCs used in this study were derived from the adult mouse brain. MSCs were isolated from the bone marrow of adult mice, and hdpPSCs were isolated from the decidua parietalis dissected from placental membranes. All stem cell populations have self-renewal capability. Whereas NPCs are capable of differentiating into neurons or glia only, MSCs exhibit multilineage potential into many mesodermal cell types and possibly into endodermal and ectodermal cells as well (reviewed in [32]). hdpPSCs are of human fetal origin and are thought to exhibit multilineage potential [33].

These results provide functional significance for the fact that APP is ubiquitously expressed and is highly conserved in evolution (reviewed in [34]). We show that sAPP $\alpha$ is a potent factor that can recover proliferation of these stem cell populations after treatment with an MMP inhibitor. The importance of our observations is supported by studies reporting that the expression of 


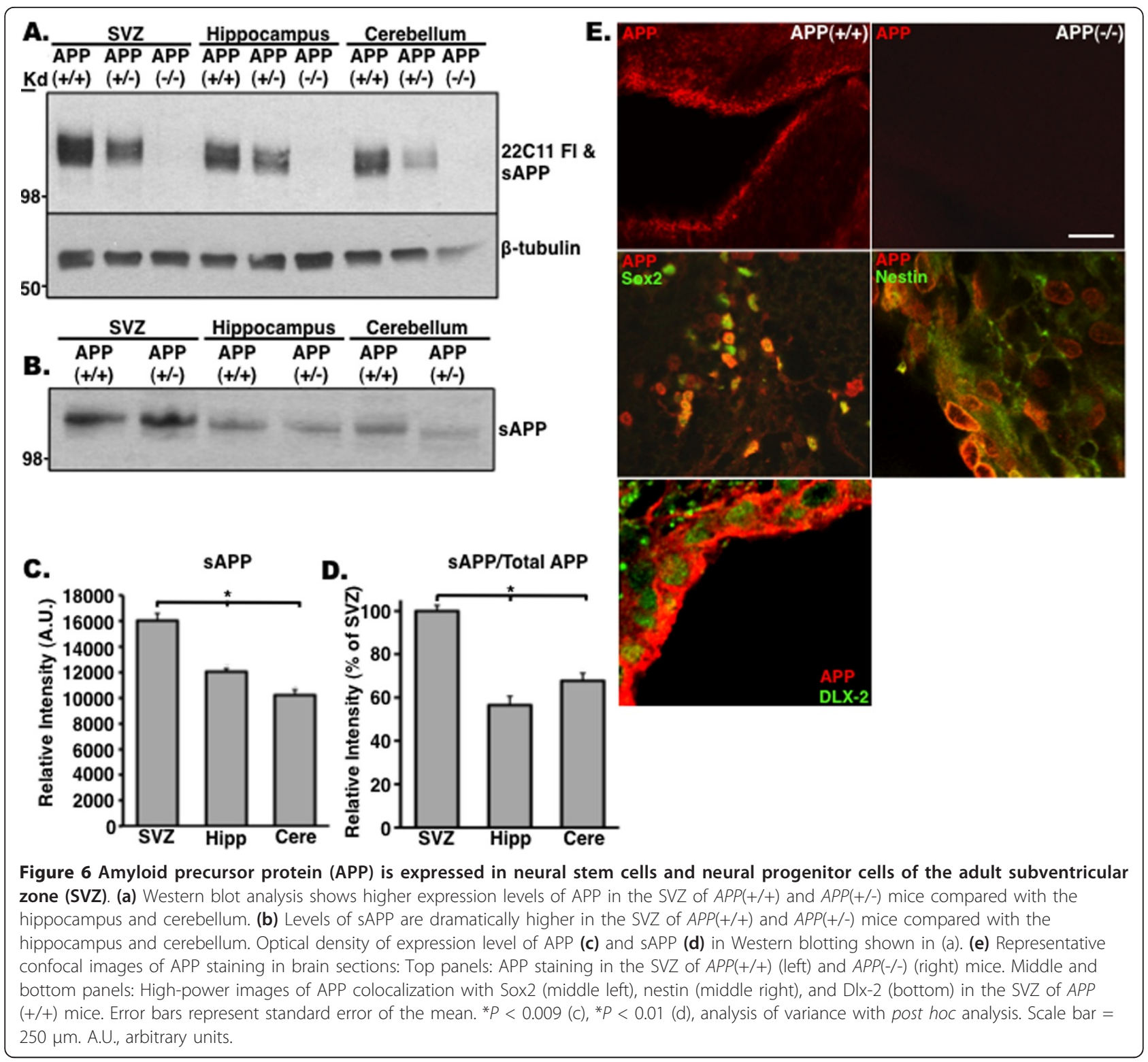

sAPP $\alpha$ can rescue behavioral and physiological deficits of $A P P$ knockout mice, such as growth and brain weight deficits, agenesis of the corpus callosum, and impaired spatial learning associated with impaired long-term potentiation, suggesting that SAPP $\alpha$ is sufficient for the execution of APP function compromised in its absence $[35,36]$.

APLP1 and APLP2 have substantial homology to APP, both within the ectodomain and particularly within the cytoplasmic tail [37]. Support for functional redundancy between APLP2 and APP/APLP1 comes from studies of combined knockouts [38]. Cleavage of APLP1 and APLP2 by $\alpha$-secretase yields SAPLP $\alpha$ of unknown function, which may play a role similar to that of SAPP $\alpha$ in NPC and other stem cell populations. As we cannot exclude a potential functional redundancy between sAPP $\alpha$ and SAPLP $2 \alpha$, we avoid a potential compensatory effect of SAPLP $\alpha$ in the present study by using the GM6001 MMP inhibitor that inhibits APLP1,2 cleavage by $\alpha$-secretase as well. Expression levels of sAPP $\alpha$ were particularly high in the SVZ. That may suggest that NPC proliferation is differentially regulated in the two neurogenic microenvironments in the adult brain [39] (and that sAPP $\alpha$ plays an important role in the SVZ specifically) or simply reflect the fact that the neurogenic population is larger in the SVZ. Expression levels of the $\alpha$-secretase, ADAM10, are significantly higher in the SVZ compared with the dentate gyrus or to the SVZ of $\operatorname{APP}(-/-)$, suggesting a correlation between $\alpha$-secretase and $\mathrm{sAPP} \alpha$ in the neurogenic regions. Like in the 


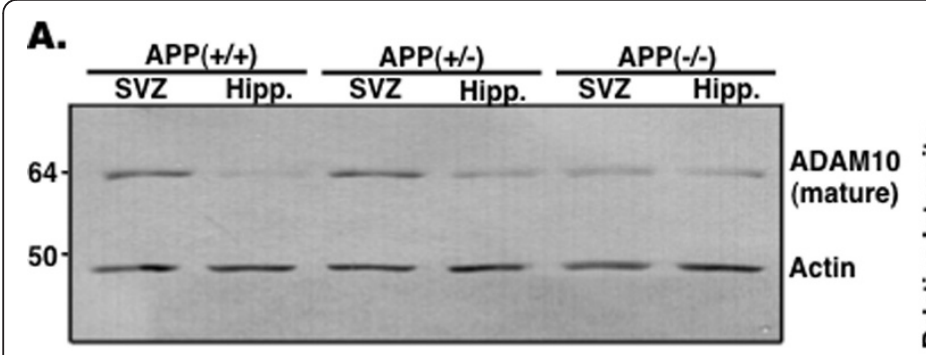

D.

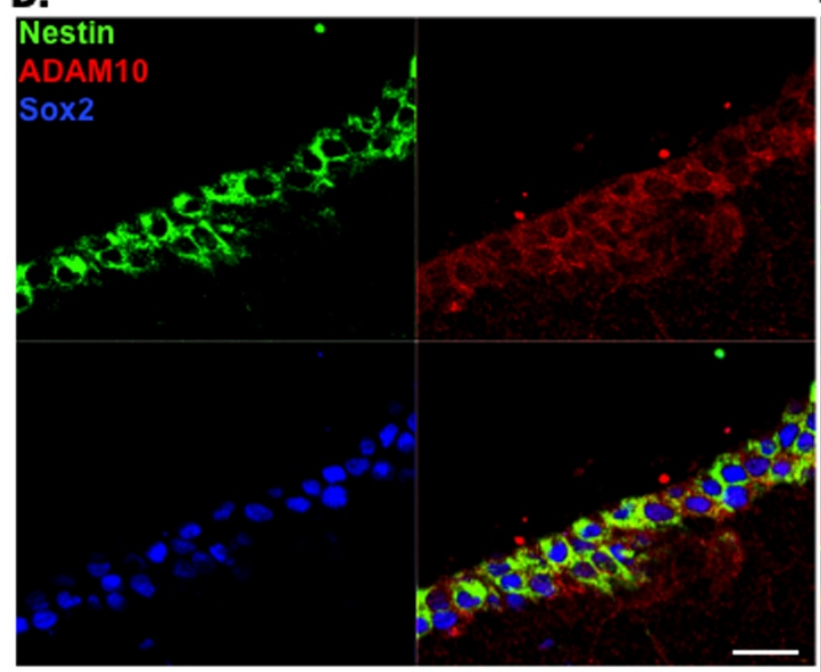

E.

B.

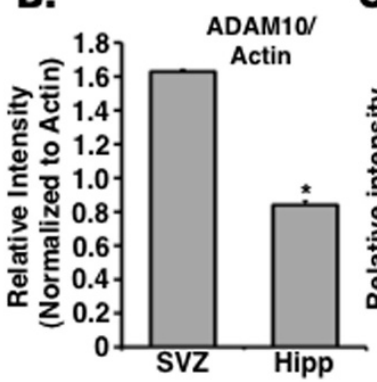

C.

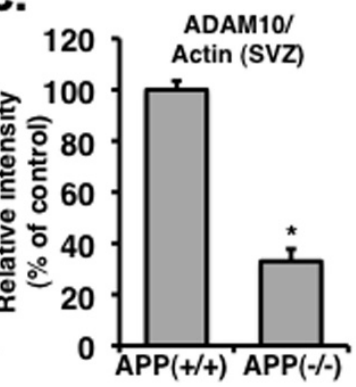

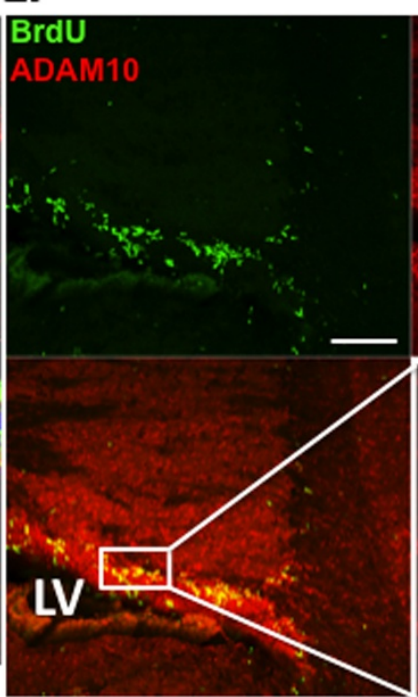

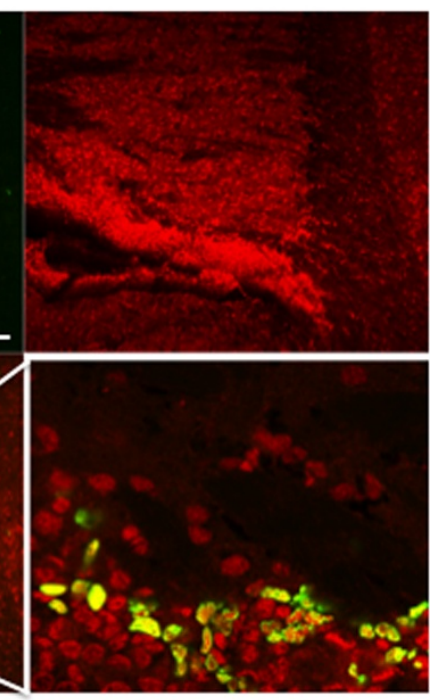

Figure 7 Enhanced levels of ADAM10 in the subventricular zone (SVZ) of adult mice. (a) Expression of the $\alpha$-secretase ADAM10 is high in the SVZ compared with the hippocampus of $A P P(+/+)$ and $A P P(+/-)$ mice, suggesting a correlation with sAPP $\alpha$ levels. (b) Quantification of four Western blots showing higher ADAM10 levels in the SVZ compared with the hippocampus. (c) Quantification of four Western blots showing that ADAM10 expression is higher in APP(+/+) SVZ compared with that of the APP(-/-). (d) Representative images of ADAM10 colocalized with Sox2 and nestin in the adult SVZ. Scale bar $=125 \mu \mathrm{m}$. (e) Representative images of ADAM10 colocalized with BrdU after a single injection 24 hours prior to sacrifice. Error bars represent standard error of the mean. ${ }^{*} P<0.001$ (b), ${ }^{*} P<0.01$ (c), Student $t$ test. Scale bar $=250 \mu \mathrm{m}$. ADAM, a disintegrin and metalloproteinase; APP, amyloid precursor protein; LV, lateral ventricle; SAPP $\alpha$, soluble amyloid precursor protein alpha.

case of sAPP $\alpha$, the higher level of ADAM10 expression in the SVZ may be a reflection of the greater population of NSCs and NPCs residing in the SVZ. While GM6001 inhibited $\alpha$-secretase activity in NPCs, MSCs, and hdpPSCs, we cannot exclude the possibility that the identity of the dominant $\alpha$-secretase in each one of these stem cell populations is different, representing a different member of the ADAM family, each of which is differentially expressed in a tissue- or niche-specific manner.

Finally, we provide an insight into the mechanism by which sAPP $\alpha$ exerts its proliferative effect in NPCs. We show that it acts in an EGF- and bFGF-independent manner. It has been suggested that, because of the presence of a heparin-binding domain adjacent to the putative growth factor domain in APP [40] and the presence of sAPP-binding sites on EGF-responsive NPCs [18], signaling of sAPP may involve other factors (such as
EGF) which also can interact with heparin. Our results suggest that any interaction of sAPP $\alpha$ and EGF or bFGF is not necessary for the proliferation-related functions of the molecule. Furthermore, we show that sAPP $\alpha$ signaling is associated with ERK/MAP kinase signaling. Increased phosphorylation of ERK is indicative of signaling through the MAP kinase pathway. In NPCs, ERK signaling is crucial for carbachol-induced increases in DNA synthesis [41], inhibiting MAP kinase signaling decreases BrdU incorporation after heparin-binding EGF activation [42], and MEK 1 and 2 inhibitor, U0126, inhibits proliferation after hypoxia/reoxygenation [43]. All of these factors point to ERK/MAP kinase as a critical pathway in the proliferation of NPCs. Another critical pathway involved in proliferation of NPCs, Akt [41-44], was not activated by SAPP $\alpha$ in vitro. Previous investigations using pharmaceutical inhibitors of either the ERK/ MAP kinase pathway or the Akt/PI3-K pathway suggest 


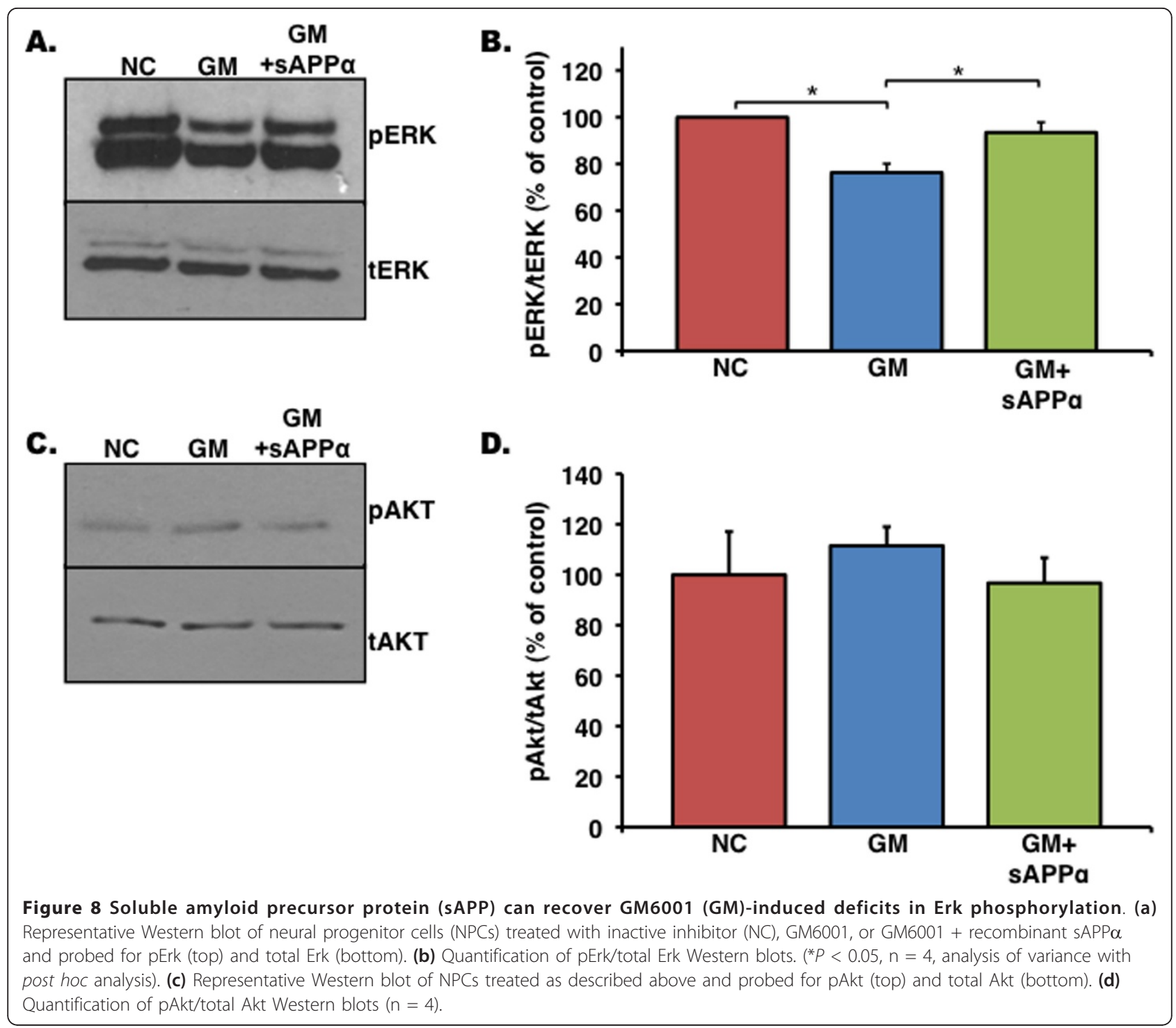

that PI3-K inhibition results in both self-renewal deficits and proliferation decline whereas MAP-kinase inhibition affected proliferation only [45].

\section{Conclusions}

In summary, we provide evidence that, by signaling through MAP kinase pathways, the evolutionarily conserved SAPP $\alpha$ regulates the proliferation of adult stem cells originating from different germ layers. Future studies should determine whether a reduction in $\alpha$-secretase activity or in SAPP $\alpha$ production or in both contributes to the aging of these stem cell populations.

\section{Abbreviations}

ADAM: a disintegrin and metalloproteinase; APP: amyloid precursor protein BCA: bicinchoninic acid; bFGF: basic fibroblast growth factor; BSA: bovine serum albumin; DMEM/F12: Dulbecco's modified Eagle's medium/F12; EDTA: ethylenediaminetetraacetic acid; EGF: epidermal growth factor; ERK: extracellular signal-regulated kinase; hdpPSC: Human decidua parietalis placenta stem cells; MAP: mitogen-activated protein; MMP: matrixmetalloproteinase; MSC: mesenchymal stem cell; NC: negative control inactive inhibitor; NPC: neural progenitor cell; NSC: neural stem cell; PBS: phosphate-buffered saline; PMSF: phenylmethylsulfonyl fluoride; rpm: revolutions per minute; SAPPa: soluble amyloid precursor protein alpha; SGL: subgranular layer of the dentate gyrus; SORLA: sortilin-related receptor with type-A repeats; SVZ: subventricular zone; TBS: Tris-buffered saline.

\section{Acknowledgements}

This study was supported by NIA AG033570 (OL), an Alzheimer's Association Young Investigator Award (OL), an Illinois Department of Public Health ADRF award $(\mathrm{OL})$, and the Brain Research Foundation $(\mathrm{OL})$.

\section{Author details}

'Department of Anatomy and Cell Biology, The University of Illinois at Chicago, 808 S Wood St. Rm. 572 Chicago, IL 60612, USA. ²Department of Surgery, The University of Illinois at Chicago, 840 S Wood St. Suite 402 Chicago, IL 60612, USA. ${ }^{3}$ Department of Obstetrics and Gynecology College of Medicine, The University of Illinois at Chicago, 1801 W. Taylor Street, Chicago, IL 60612, USA. 


\section{Authors' contributions}

MPD carried out experiments and data analysis and participated in manuscript writing.

$A B$ and $Z S$ each collaborated on experiments and participated in experimental design and manuscript writing. OL oversaw studies and participated in study design, data analysis, and manuscript writing. All authors read and approved the final manuscript.

\section{Competing interests}

The authors declare that they have no competing interests.

Received: 1 July 2011 Accepted: 30 August 2011

Published: 30 August 2011

\section{References}

1. Thinakaran G, Koo EH: Amyloid precursor protein trafficking, processing, and function. J Biol Chem 2008, 283:29615-29619.

2. Small SA, Gandy S: Sorting through the cell biology of Alzheimer's disease: intracellular pathways to pathogenesis. Neuron 2006, 52:15-31.

3. Sisodia SS: Beta-amyloid precursor protein cleavage by a membranebound protease. Proc Natl Acad Sci USA 1992, 89:6075-6079.

4. Sisodia SS, Koo EH, Hoffman PN, Perry G, Price DL: Identification and transport of full-length amyloid precursor proteins in rat peripheral nervous system. J Neurosci 1993, 13:3136-3142.

5. De Strooper B: Alzheimer's disease. Closing in on gamma-secretase. Nature 2000, 405:627-629.

6. Lammich S, Kojro E, Postina R, Gilbert S, Pfeiffer R, Jasionowski M, Haass C, Fahrenholz F: Constitutive and regulated alpha-secretase cleavage of Alzheimer's amyloid precursor protein by a disintegrin metalloprotease. Proc Natl Acad Sci USA 1999, 96:3922-3927.

7. Asai M, Hattori C, Szabo B, Sasagawa N, Maruyama K, Tanuma S, Ishiura S: Putative function of ADAM9, ADAM10, and ADAM17 as APP alphasecretase. Biochem Biophys Res Commun 2003, 301:231-235.

8. Buxbaum JD, Liu KN, Luo Y, Slack JL, Stocking KL, Peschon JJ, Johnson RS, Castner BJ, Cerretti DP, Black RA: Evidence that tumor necrosis factor alpha converting enzyme is involved in regulated alpha-secretase cleavage of the Alzheimer amyloid protein precursor. J Biol Chem 1998, 273:27765-27767.

9. Postina R, Schroeder A, Dewachter I, Bohl J, Schmitt U, Kojro E, Prinzen C, Endres K, Hiemke C, Blessing M, Flamez P, Dequenne A, Godaux E, van Leuven F, Fahrenholz F: A disintegrin-metalloproteinase prevents amyloid plaque formation and hippocampal defects in an Alzheimer disease mouse model. J Clin Invest 2004, 113:1456-1464

10. Yan R, Munzner JB, Shuck ME, Bienkowski MJ: BACE2 functions as an alternative alpha-secretase in cells. J Biol Chem 2001, 276:34019-34027.

11. Endres K, Postina R, Schroeder A, Mueller U, Fahrenholz F: Shedding of the amyloid precursor protein-like protein APLP2 by disintegrinmetalloproteinases. FEBS J 2005, 272:5808-5820.

12. LaVoie MJ, Selkoe DJ: The Notch ligands, Jagged and Delta, are sequentially processed by alpha-secretase and presenilin/gammasecretase and release signaling fragments. J Biol Chem 2003, 278:34427-34437.

13. Jorissen E, Prox J, Bernreuther C, Weber S, Schwanbeck R, Serneels L, Snellinx A, Craessaerts K, Thathiah A, Tesseur I, Bartsch U, Weskamp G, Blobel CP, Glatzel M, De Strooper B, Saftig P: The disintegrin/ metalloproteinase ADAM10 is essential for the establishment of the brain cortex. J Neurosci 2010, 30:4833-4844.

14. Saitoh T, Sundsmo M, Roch JM, Kimura N, Cole G, Schubert D, Oltersdorf T, Schenk DB: Secreted form of amyloid beta protein precursor is involved in the growth regulation of fibroblasts. Cell 1989, 58:615-622.

15. Pietrzik CU, Hoffmann J, Stober K, Chen CY, Bauer C, Otero DA, Roch JM, Herzog V: From differentiation to proliferation: the secretory amyloid precursor protein as a local mediator of growth in thyroid epithelial cells. Proc Natl Acad Sci USA 1998, 95:1770-1775.

16. Ohsawa I, Takamura C, Morimoto T, Ishiguro M, Kohsaka S: Amino-terminal region of secreted form of amyloid precursor protein stimulates proliferation of neural stem cells. Eur J Neurosci 1999, 11:1907-1913.

17. Rossjohn J, Cappai R, Feil SC, Henry A, McKinstry WJ, Galatis D, Hesse L, Multhaup G, Beyreuther K, Masters CL, Parker MW: Crystal structure of the $\mathrm{N}$-terminal, growth factor-like domain of Alzheimer amyloid precursor protein. Nat Struct Biol 1999, 6:327-331.
18. Caille I, Allinquant B, Dupont E, Bouillot C, Langer A, Muller U, Prochiantz A: Soluble form of amyloid precursor protein regulates proliferation of progenitors in the adult subventricular zone. Development 2004, 131:2173-2181.

19. Rohe M, Carlo AS, Breyhan H, Sporbert A, Militz D, Schmidt V, Wozny C, Harmeier A, Erdmann B, Bales KR, Wolf S, Kempermann G, Paul SM, Schmitz D, Bayer TA, Willnow TE, Andersen OM: Sortilin-related receptor with A-type repeats (SORLA) affects the amyloid precursor proteindependent stimulation of ERK signaling and adult neurogenesis. J Biol Chem 2008, 283:14826-14834.

20. Demars M, Hu YS, Gadadhar A, Lazarov O: Impaired neurogenesis is an early event in the etiology of familial Alzheimer's disease in transgenic mice. J Neurosci Res 2010, 88:2103-2117.

21. Polchert D, Sobinsky J, Douglas G, Kidd M, Moadsiri A, Reina E, Genrich K, Mehrotra S, Setty S, Smith B, Bartholomew A: IFN-gamma activation of mesenchymal stem cells for treatment and prevention of graft versus host disease. Eur J Immunol 2008, 38:1745-1755.

22. Strakova Z, Livak M, Krezalek M, Ihnatovych I: Multipotent properties of myofibroblast cells derived from human placenta. Cell Tissue Res 2008, 332:479-488.

23. Zheng H, Jiang M, Trumbauer ME, Hopkins R, Sirinathsinghji DJ, Stevens KA, Conner MW, Slunt HH, Sisodia SS, Chen HY, Van der Ploeg LH: Mice deficient for the amyloid precursor protein gene. Ann N Y Acad Sci 1996, 777:421-426

24. Zheng $H$, Jiang M, Trumbauer ME, Sirinathsinghji DJ, Hopkins R, Smith DW, Heavens RP, Dawson GR, Boyce S, Conner MW, Stevens KA, Slunt HH, Sisoda SS, Chen HY, Van der Ploeg LH: beta-Amyloid precursor proteindeficient mice show reactive gliosis and decreased locomotor activity. Cell 1995, 81:525-531.

25. National Institutes of Health Guide for the Care and Use of Laboratory Animals [http://grants.nih.gov/grants/olaw/Guide-for-the-Care-and-use-oflaboratory-animals.pdf].

26. Bazán E, Alonso FJ, Redondo C, López-Toledano MA, Alfaro JM, Reimers D, Herranz AS, Paíno CL, Serrano AB, Cobacho N, Caso E, Lobo MV: In vitro and in vivo characterization of neural stem cells. Histol Histopathol 2004, 19:1261-1275.

27. Alvarez-Buylla A, Garcia-Verdugo JM: Neurogenesis in adult subventricular zone. J Neurosci 2002, 22:629-634.

28. Doetsch F, Petreanu L, Caille I, Garcia-Verdugo JM, Alvarez-Buylla A: EGF converts transit-amplifying neurogenic precursors in the adult brain into multipotent stem cells. Neuron 2002, 36:1021-1034.

29. Learish RD, Bruss MD, Haak-Frendscho M: Inhibition of mitogen-activated protein kinase kinase blocks proliferation of neural progenitor cells. Brain Res Dev Brain Res 2000, 122:97-109.

30. Greenberg SM, Kosik KS: Secreted beta-APP stimulates MAP kinase and phosphorylation of tau in neurons. Neurobiol Aging 1995, 16:403-407, discussion 407-408.

31. Wehner S, Siemes C, Kirfel G, Herzog V: Cytoprotective function of sAppalpha in human keratinocytes. Eur J Cell Biol 2004, 83:701-708,

32. Kuhn NZ, Tuan RS: Regulation of stemness and stem cell niche of mesenchymal stem cells: implications in tumorigenesis and metastasis. $J$ Cell Physiol 2010, 222:268-277.

33. Nlancheran S, Michalska A, Peh G, Wallace EM, Pera M, Manuelpillai U: Stem cells derived from human fetal membranes display multilineage differentiation potential. Biol Reprod 2007, 77:577-588.

34. Selkoe DJ: Alzheimer's disease: genes, proteins, and therapy. Physiol Rev 2001, 81:741-766.

35. Muller U, Cristina N, Li ZW, Wolfer DP, Lipp HP, Rulicke T, Brandner S, Aguzzi A, Weissmann C: Behavioral and anatomical deficits in mice homozygous for a modified beta-amyloid precursor protein gene. Cell 1994, 79:755-765.

36. Ring S, Weyer SW, Kilian SB, Waldron E, Pietrzik CU, Filippov MA, Herms J, Buchholz C, Eckman CB, Korte M, Wolfer DP, Müller UC: The secreted betaamyloid precursor protein ectodomain APPs alpha is sufficient to rescue the anatomical, behavioral, and electrophysiological abnormalities of APP-deficient mice. J Neurosci 2007, 27:7817-7826.

37. Slunt HH, Thinakaran G, Von Koch C, Lo AC, Tanzi RE, Sisodia SS: Expression of a ubiquitous, cross-reactive homologue of the mouse beta-amyloid precursor protein (APP). J Biol Chem 1994, 269:2637-2644.

38. Heber S, Herms J, Gajic V, Hainfellner J, Aguzzi A, Rülicke T, von Kretzschmar H, von Koch C, Sisodia S, Tremml P, Lipp HP, Wolfer DP, 
Müller U: Mice with combined gene knock-outs reveal essential and partially redundant functions of amyloid precursor protein family members. J Neurosci 2000, 20:7951-7963.

39. Suh H, Deng W, Gage FH: Signaling in adult neurogenesis. Annu Rev Cell Dev Biol 2009, 25:253-275.

40. Corrigan F, Pham CL, Vink R, Blumbergs PC, Masters CL, van den Heuvel C, Cappai R: The neuroprotective domains of the amyloid precursor protein, in traumatic brain injury, are located in the two growth factor domains. Brain Res 2011, 1378:137-143.

41. Li BS, Ma W, Zhang L, Barker JL, Stenger DA, Pant HC: Activation of phosphatidylinositol-3 kinase (PI-3K) and extracellular regulated kinases (Erk1/2) is involved in muscarinic receptor-mediated DNA synthesis in neural progenitor cells. J Neurosci 2001, 21:1569-1579.

42. Jin K, Mao XO, Del Rio Guerra G, Jin L, Greenberg DA: Heparin-binding epidermal growth factor-like growth factor stimulates cell proliferation in cerebral cortical cultures through phosphatidylinositol 3'-kinase and mitogen-activated protein kinase. J Neurosci Res 2005, 81:497-505.

43. Sung SM, Jung DS, Kwon CH, Park JY, Kang SK, Kim YK: Hypoxia/ reoxygenation stimulates proliferation through PKC-dependent activation of ERK and Akt in mouse neural progenitor cells. Neurochem Res 2007, 32:1932-1939.

44. Wang L, Gang Zhang Z, Lan Zhang R, Chopp M: Activation of the PI3-K/ Akt pathway mediates CGMP enhanced-neurogenesis in the adult progenitor cells derived from the subventricular zone. I Cereb Blood Flow Metab 2005, 25:1150-1158.

45. Torroglosa A, Murillo-Carretero M, Romero-Grimaldi C, Matarredona ER, Campos-Caro A, Estrada C: Nitric oxide decreases subventricular zone stem cell proliferation by inhibition of epidermal growth factor receptor and phosphoinositide-3-kinase/Akt pathway. Stem Cells 2007, 25:88-97.

doi:10.1186/scrt77

Cite this article as: Demars et al: Soluble amyloid precursor protein: a novel proliferation factor of adult progenitor cells of ectodermal and mesodermal origin. Stem Cell Research \& Therapy 2011 2:36.

\section{Submit your next manuscript to BioMed Central and take full advantage of:}

- Convenient online submission

- Thorough peer review

- No space constraints or color figure charges

- Immediate publication on acceptance

- Inclusion in PubMed, CAS, Scopus and Google Scholar

- Research which is freely available for redistribution

Submit your manuscript at www.biomedcentral.com/submit 